\title{
Correction to: Effects of Environmental Stress and Gender on Associations among Symptoms of Depression and the Serotonin Transporter Gene Linked Polymorphic Region (5-HTTLPR)
}

\author{
Beverly H. Brummett ${ }^{1}$. Stephen H. Boyle ${ }^{1}$. llene C. Siegler ${ }^{1}$. Cynthia M. Kuhn ${ }^{2}$. Allison Ashley-Koch ${ }^{3}$. \\ Charles R. Jonassaint ${ }^{4} \cdot$ Stephan Züchner ${ }^{5} \cdot$ Ann Collins $^{3} \cdot$ Edward C. Suarez $^{1} \cdot$ Redford B. Williams $^{1}$
}

Published online: 21 December 2020

(c) Springer Science+Business Media, LLC, part of Springer Nature 2021

\section{Correction to: Behavior Genetics (2008) 38:34-43 https://doi.org/10.1007/s10519-007-9172-1}

After the publication of original article, the Editor was notified by Duke University that they have determined the authorship to be incomplete. Consequently, Dr. Edward Suarez has been added as a co-author to this article to represent his contribution to the conception and design of the work and acquisition of the data.

Publisher's Note Springer Nature remains neutral with regard to jurisdictional claims in published maps and institutional affiliations.

The original article can be found online at https://doi.org/10.1007/ s10519-007-9172-1.

Beverly H. Brummett

brummett@acpub.duke.edu

1 Department of Psychiatry and Behavioral Medicine, Duke University Medical Center, Box 2969, Durham, NC 27710 , USA

2 Department of Pharmacology and Cancer Biology, Duke University Medical Center, Durham, NC, USA

3 Center for Human Genetics, Duke University Medical Center, Durham, NC, USA

4 Department of Psychology, Duke University, Durham, USA

5 Miami Institute of Human Genomics, University of Miami Miller School of Medicine, Miami, FL, USA 